\title{
THE
}

\section{A review of early influences on physical activity and sedentary behaviors of preschool-age children in high-income countries}

Ana Cristina Lindsay

Mary L. Greaney

University of Rhode Island, mgreaney@uri.edu

Sherrie F. Wallington

Tatiana Mesa

Carlos F. Salas

Follow this and additional works at: https://digitalcommons.uri.edu/kinesiology_facpubs

The University of Rhode Island Faculty have made this article openly available. Please let us know how Open Access to this research benefits you.

This is a pre-publication author manuscript of the final, published article.

Terms of Use

This article is made available under the terms and conditions applicable towards Open Access Policy Articles, as set forth in our Terms of Use.

\section{Citation/Publisher Attribution}

Lindsay AC, Greaney ML, Wallington SF, Mesa T, Salas CF. A review of early influences on physical activity and sedentary behaviors of preschool-age children in high-income countries. J Spec Pediatr Nurs. 2017;22:e12182. https://doi.org/10.1111/jspn.12182

Available at: https://doi.org/10.1111/jspn.12182 
A review of early influences on physical activity and sedentary behaviors of preschoolage children in high-income countries

Ana Cristina Lindsay ${ }^{1,2}$; Mary L. Greaney ${ }^{3}$; Sherrie F. Wallington ${ }^{4}$; Tatiana Mesa ${ }^{1}$; Carlos F. Salas ${ }^{1}$

1. University of Massachusetts Boston, Exercise and Health Sciences Department, College of Nursing and Health Sciences, Boston, MA, USA

2. Harvard School of Public Health, Department of Nutrition, Boston, MA, USA University of Rhode Island, Health Studies \& Department of Kinesiology, Kingston, RI, USA

3. University of Rhode Island, Department of Kinesiology

4. Lombardi Comprehensive Cancer Center, Georgetown University Medical Center, Washington, DC, USA

\section{Authors' email addresses:}

Ana Cristina Lindsay: Ana.Lindsay@umb.edu

Mary L. Greaney: mgreaney@uri.edu

Sherrie F. Wallington: slw49@georgetown.edu

Tatiana Mesa: Tatiana.Mesa001@umb.edu

Carlos Salas: Carlos.Salas001@umb.edu

\section{Address for Correspondence:}

Ana Cristina Lindsay, DDS, MPH, DrPH

Associate Professor

Department of Exercise and Health Sciences

University of Massachusetts Boston

100 Morrissey Boulevard

Boston, MA 02125

Phone: 617-287-7579

Email: Ana.Lindsay@umb.edu 
40 Purpose: Promoting physical activity (PA) is a key component of preventing and controlling

41 childhood obesity. Despite well-documented benefits of PA, globally, rates of physical

42 activity among young children have declined over the past decades, and most children are not

43 accruing sufficient physical activity daily. Helping children develop the foundation for PA

44 habits early in life is critical for the promotion of health in childhood and prevention of

45 chronic diseases later in life, and will ultimately promote longer and healthier lives for

46 individuals and the general population. The purpose of this review is to provide a synthesis of

47 current evidence on influences on PA and sedentary behaviors of preschool-age children in

48 high-income countries.

49 Design and Methods: A systematic review of three databases was performed. Studies

50 conducted in high-income countries and published from 2000 onwards that addressed

51 influences on physical activity and sedentary behaviors of preschool-age children were

52 identified and reviewed. Additionally, reference lists of identified articles and relevant

53 published reviews were reviewed. Studies that met the following inclusion criteria were

54 considered: (a) sample included preschoolers (age $\leq 5$ years); (b) PA and/or sedentary

55 behaviors or factors associated with PA and/or sedentary behaviors was assessed; (c)

56 published in English; (d) used either quantitative or qualitative methods; and (e) conducted in

57 a high-income country. Data were extracted from selected studies to identify influences on PA

58 and sedentary behaviors of preschool-age children and organized using the social-ecological

59 model according to multiple levels of influence.

60 Results: Results from included studies identify multiple factors that influence PA and

61 sedentary behaviors of young children in high-income countries at the various levels of the 
62 social-ecological model including intrapersonal, interpersonal, environmental, organizational, 63 and policy.

64 Practice Implications: Given pediatric nurses' role as primary care providers, and their

65 frequent and continued contact with parents and their children throughout childhood through

66 well-child visits, immunization, and minor acute illnesses, they are well positioned to promote

67 and support the development of early healthful PA habits of children starting in early

68 childhood.

69

70 Keywords: physical activity, sedentary behaviors, preschool-age children, social-ecological

71 model

72

73

74

75

76

77

78

79

80

81

82

83

84 


\section{INTRODUCTION}

Several high-income countries including the United States, United Kingdom, Australia, and Canada, have developed physical activity (PA) guidelines specific to preschoolage children recommending that children this age engage in at least 120 to 180 minutes of total PA (including light PA and moderate-to-vigorous PA) daily (Commonwealth of Australia, Department of Health and Ageing, 2010; Department of Health, Physical Activity, Health Improvement and Protection, 2011; NASPE, 2009; Okely, Salmon, Trost, \& Hinkley, 2008; Tremblay et al., 2012).

In the United States, the National Association for Sport and Physical Education (NASPE, 2009) has developed PA guidelines from infancy to the age of 5 years. These guidelines advocate increasing opportunities for preschoolers to engage in a minimum of 120 minutes of daily PA in the form of 60 minutes of structured activity and 60 minutes of unstructured or spontaneous active play. Similarly, the American Academy of Pediatrics recommends that clinicians encourage parents to increase physical activities and decrease time spent in sedentary activities (e.g., screen-time, time spent indoors, etc.) in a manner compatible with the developmental level of a child (AAP, 2006).

Furthermore, high-income countries including the United States, Canada and Australia have created stringent screen-viewing guidelines in response to the increasing rates of sedentary behaviors among preschool-aged children. For example, the American Academy of

Pediatrics recommends that screen-viewing be limited to a maximum of two hours per day for children over two years of age (AAP, 2006). Both Canada (Tremblay et al., 2012) and Australia (Commonwealth of Australia, Department of Health and Ageing, 2010) have more stringent screen-viewing guidelines for young children, with both countries recommending 
that screen-viewing for children 1-4 years of age in Canada and 2-5 years of age in Australia be limited to 1 hour per day.

Physical activity is a key component of energy balance consistent with healthy patterns of physical growth and weight status; thus, promoting PA is essential to prevention of childhood obesity (O’Dwyer et al., 2012; Pratt, Epping, \& Dietz, 2009). Physically active children have healthier cardiovascular profiles, leaner body frames, and higher peak bone mass compared to physically inactive children (AAP, 2006; Goldfield, Harvey, Grattan, \& Adamo, 2012; Hodges, Smith, Tidwell, \& Berry, 2013; O’Dwyer, Fairclough, Knowles, \& Stratton, 2012). In addition to regulating body weight and improving body composition, PA improves psychological and social wellbeing (AAP, 2006; Beets et al., 2011; Hodges et al., 2013; O’Dwyer et al., 2012).

Despite well-documented benefits of PA for children, activity levels of children across the globe have declined over the past decades, and most preschool-age children are not accruing the recommended levels of moderate-vigorous physical activity (MVPA) daily (Montgomery et al., 2004; Pate et al., 2015). Moreover, an increasing number of studies document excessive screen-viewing time including television, computers, smartphones, etc. among preschool-age children (Asplund, Kair, Arain, Cervantes, Oreskovic, Zuckerman, 2015; Beets, Bornstein, Dowda, \& Pate, 2011; Davison et al., 2011; Ekelund, Brage, \& Wareham, 2004; Garriguet, Carson, Colley, Janssen, Timmons \& Tremblay, 2016; Lampard, Jurkowski, Davison, 2013; Mendoza, Zimmerman, \& Christakis, 2007; Pate et al., 2015; Vale, Santos, Soares-Miranda, Silva, \& Mota, 2010; Vandewater, Bickham, \& Lee, 2006). Physical activity and sedentary behaviors are complex and influenced by interacting multi-level factors that either facilitate or hinder PA and sedentary behaviors in young 
131 children. The social-ecological model has been extensively used to help health professionals 132 and researchers identify and understand how the various multi-level influences interact to 133 form individual's PA opportunities and choices. Consistent evidence shows that addressing 134 multiple levels of the social-ecological model is associated with greater change in behaviors 135 including PA (Sallis, Cervero, Asher, Henderson, Kraft \& Kerr, 2006). Moreover, the social136 ecological model recognizes the context and interaction typical of preschool-aged children 137 and provide an important framework for developing interventions that address the social and 138 physical environments and public policy for improving PA and reducing sedentary behaviors 139 of young children (Sallis, Cervero, Asher, Henderson, Kraft \& Kerr, 2006). behaviors among young children, this review sought to elucidate early influences on PA and

142 sedentary behaviors of preschool-age children in high-income countries by using the social143 ecological model to identify and organize facilitators and/or barriers to PA and sedentary 144 behaviors of young children.

\section{METHODS}

We searched three electronic databases (PubMed, SPORTDiscus, and PsycINFO) to

147 identify studies published from January 2000 onward that addressed influences on PA and 148 sedentary behaviors among preschool-age children (age $\leq 5$ years) in high-income countries.

149 We used the criteria from the Organization for Economic Cooperation and Development 150 (OECD) and The World Bank to define high-income countries, which defines high-income as 151 a country with a gross national income per capita above US\$ 12,475 in 2015, calculated using 152 the Atlas method (The World Bank, 2013). Additionally, we searched the references of 153 identified studies and relevant published reviews. We used the combination of the following 
154 key search terms: physical activity, inactivity, lifestyle, sedentary behavior, screen, preschool,

155 children, overweight, obese/obesity, prevention, and influences. Studies that met the following

156 inclusion criteria were reviewed: (a) sample included preschoolers (age $\leq 5$ years); (b)

157 measured PA and sedentary behaviors and/or factors associated with PA and sedentary

158 behaviors; (c) published in English; (d) used either quantitative or qualitative methods; (e)

159 conducted in a high-income country. Exclusion criteria included the following: (a) the study

160 sample was children with preexisting conditions (e.g., cardiac disease, hypertension, diabetes

161 mellitus, dyslipidemia, or mental illness) that could constrain PA; (b) review articles; and (c)

162 articles published only in languages other than English. One author read all the abstracts of

163 identified full-text papers meeting inclusion criteria. Identified papers were reviewed by two

164 of the authors, who used the social-ecological model as a framework to organize identified

165 factors influencing PA. Figure 1 shows the literature search strategy.

[Figure 1 here]

167

168

169

170

171

172

173

174

175

176

177

\section{Theoretical Model for Examining Influences on Preschool Children's Physical Activity}

The social-ecological model provided the conceptual framework for this review

(McLeroy, Bibeau, Steckler, \& Glanz, 1988) and was used to organize influences on

preschool-age children's PA by level: (a) intrapersonal (e.g., age, gender, material

circumstances, ethnicity, etc.); (b) interpersonal (e.g., social support, networks, etc.); (c)

environmental (e.g., access and proximity to parks, etc.); (d) organizational (e.g., child care,

federally funded nutrition programs such as WIC, etc.); and (e) policy (e.g., state policies and regulations related to nutrition and PA in child care settings, etc.). This framework posits that

factors at each level interact and influence health behaviors (McLeroy et al., 1998). Table 1

shows a breakdown of the studies reviewed according to the social-ecological model. 
[Figure 2 and Table 1 here]

179

180

181

182

183

184

185

186

187

188

189

190

191

192

193

194

195

196

197

198

199

RESULTS

\section{Individual/Intrapersonal Influences}

Socioeconomic and demographic factors. Parents' socioeconomic status (SES) and educational level are associated with preschool children's early PA behaviors (Dawson-Hahn, Fesinmeyer, \& Mendoza, 2015; Salmon, Owen, Crawford, Bauman, \& Sallis, 2003). Jones, Hendricks, and Draper (2014) found that among children aged 4-5 years old attending preschools, parents with low-income reported that their children spent $93 \%$ of time indoors compared to $79 \%$ reported by parents with mid/high-income. Parental socioeconomic status is also associated with preschool children's early sedentary behaviors. Levin, Martin \& Riner (2004) found excessive TV viewing habits among a sample of low-income 4-year old children enrolled in Head Start in South Carolina.

Differences in PA by sex exist (Vale et al., 2010; Van Cauwenberghe et al., 2012), and across SES and demographic strata (Vale et al., 2010; Van Cauwenberghe, Jones, Hinkley, Crawford, \& Okely, 2012), with boys being more active than girls (Finn, Johannsen, \& Specker, 2002; Pate, Pfeiffer, Trost, Ziegler, \& Dowda, 2004).

Children's PA and sedentary behaviors may also vary according to family structure. Controlling for household SES and child age, Bagley, Salmon, and Crawford (2006) determined that boys without siblings spent more time watching TV compared to those who had siblings. They also found that girls from single-parent families spent significantly more time watching TV compared to girls from two-parent families, and girls with siblings were more physically active compared to those who were the only child. 

Fakhouri, Hughes, Brody, Kit, \& Ogden, 2013; Kuepper-Nybelen et al., 2005; Kumanyika \& Grier, 2006).

A few studies have examined the associations between ethnicity and preschool children's PA (Dawson-Hahn, Fesinmeyer \& Mendoza, 2015; Fitzgibbon et al., 2011; Fitzgibbon et al., 2006; O’Connor et al., 2014; Toselli, Zaccagni, Celenza, Albertini \& Gualdi-Russo, 2015). Dawson-Hahn, Fesinmeyer \& Mendoza (2015) found that the majority of Latino preschool-aged children attending Head Start programs exceeded US national and international guidelines of physical activity duration. A study conducted in Italy among parents of Italian and immigrant preschool-aged children found that physical activity was significantly higher in Italians than in immigrants (Toselli et al., 2015).

Limited research exists examining the association between acculturation levels and preschool-age children's PA, and the limited research shows mixed results (Soltero, Cerin, Lee \& O’Connor, 2016; O’Connor et al., 2014; Gallagher, 2010). A recent study with 240 of preschool-aged children showed that Latino parents' acculturation levels moderated the relationship between perceptions of disorder and crime, which in turn, influenced parenting practices that discourage child physical activity due to safety concerns were associated with increased perceptions of traffic hazards, physical and social disorder and perceived stranger danger (Soltero, Cerin, Lee \& O’Connor, 2016). Another study with also conducted with Latino parents of preschool-aged children showed that cultural variables only had a weak main effect on PA parenting practices, specifically on discouraging PA due to safety concerns (O’Connor et al., 2014). A qualitative study with Mexican-American mothers showed that 
223 mothers' acculturation levels influenced their views of the type of physical activity children

224 should engage in depended on the age and maturity of the child (Gallagher, 2010). Previous

225 research highlights a need for further study of associations between acculturation and

226 preschoolers' PA in Western cultures (O'Connor et al., 2014; Suen, Cerin, \& Wua, 2015).

Cespedes, McDonald, Haines, Bottino, and Taveras (2013) examined obesity-related

228 behaviors in urban, low-income, and non-U.S.- and U.S.-born racial/ethnic minority

229 preschool-age children (34\% Black, 52\% Hispanic), and found that time spent in active play

230 was lower among children whose parents were born outside the U.S. than among those whose

231 parents were U.S.-born, after adjusting for parental education.

232 Interpersonal Influences

233 Parental physical activity. Parental PA and sedentary behaviors are important

234 determinants of their preschool-aged children's PA and sedentary behaviors. Ruiz, Gesell,

235 Buchowski, Lambert, and Barkin (2011) determined that Latino parents who are less

236 physically active and more sedentary had children who were more sedentary and less active

237 than Latino parents who were more physically active. A similar study found weak correlations

238 between mild and moderate parental PA and their 3- and 4-year-old children's PA (Taylor

239 et al., 2009). A study conducted in Canada by Carson, Stearns, and Janssen (2015) examined

240 the associations between parental PA and screen time behaviors and their young children's

241 behavior (61\% aged $1-3,35 \%$ aged $4-5)$ and found that parents in the lowest quartile

242 of PA were 2.77 times more likely to have a child in the lowest quartile of PA compared

243 with parents in the highest quartile. Relationships were stronger in two parent homes than in

244 single-parent homes. Furthermore, parents in the second, third, and fourth screen time

245 quartiles were significantly more likely to have a child in the highest quartile of screen time 
compared with parents in quartile one. Similar, a recent study conducted in Australia found that maternal self-reported co-participation in sedentary behavior and provision of child opportunities for physical activity was associated with children's physical activity (Hnatiuk, Ridgers, salmon \& Hesketh, 2016).

Parental beliefs and attitudes. Parents' perceptions, beliefs, and attitudes toward PA may influence their young children's PA behaviors (Dwyer, Higgs, Hardy, \& Baur, 2008; Hesketh et al., 2013; Hinkley, Salmon, Okely, Crawford, \& Hesketh, 2011; Loprinzi \& Trost, 2010; O’Connor, Chen, Baranowski, Thompson, \& Baranowski, 2013; Zecevic, Tremblay, Lovsin, \& Michel, 2010). Parental belief that participating in PA is important is associated with their children's participation in both organized and free-time PA (Sawyer et al., 2014). Children whose parents hold positive attitudes toward PA (e.g., PA is important to overall health) are more active compared to those whose parents do not hold these positive attitudes (Sawyer et al., 2014). Similarly, Zecevic and colleagues (2010) determined that children of parents who view PA as enjoyable engage in significantly more PA than children did whose parents did not view PA positively.

Parental concerns. Parents of preschool-age children have reported that their concerns about safety inhibit their children's PA (Dwyer et al., 2008; O'Connor, Chen, et al., 2013; Soltero et al., 20016; Suen et al., 2015), including concerns related to neighborhood and community safety (e.g., crime, traffic) (Dwyer et al., 2008; Soltero et al., 2016). In addition, parental concerns about excess screen time are also associated with children's PA levels (He, Irwin, Sangster Bouck, Tucker, \& Pollett, 2005; De Decker et al., 2012).

Parenting styles. Parenting styles are psychological constructs that represent broad and standard strategies that parents use in child rearing (Baumrind, 1971). Overall parenting 
style encompasses broader patterns of how parents respond and demand to their children (Baumrind, 1971). Four parenting styles have been defined: 1) authoritarian (demand obedience); 2) authoritative (use reasoning); 3) permissive (acquiesce to child's demands) and 4) uninvolved. Only one study included in this review examined the association between parenting styles and preschool-age children's PA levels, and no association was found between parenting styles and time spent in active play nor did parenting styles moderate the relationship between parental support and child active play (Schary, Cardinal, Loprinzi, 2012).

Parenting Practices. Parenting practices describe context-specific behaviors such as what a parent does to facilitate physical activity. A growing, but still limited literature exists on studies that have examined the influence of parenting practices on young children's PA behaviors (Hesketh et al., 2013; O'Connor, Chen, et al., 2013; Oliver, Schofield, \& Schluter, 2010; Zecevic, Tremblay, Lovsin and Michel, 2010; Dowda et al., 2011; Hesketh et al., 2014). Results of these studies show that some parental practices, such as encouraging PA, setting rules, providing transportation, paying fees and tuition, parental modeling of PA, and engaging in PA activities with children are associated with PA behaviors of preschool-age children (Hesketh et al., 2014; O'Connor, Chen, et al., 2013; Vanderwater et al., 2005; Veitch, Hume, Salmon, Crawford, \& Ball, 2013).

An important parenting practice is parental support for physical activity. Available research shows that children are more likely to be active if parents are supportive of them being physically active in a number ways, but especially by providing encouragement, participating in PA together, taking children to places where they can be physically active, and enrolling them in organized activities such as sports classes (Davison et al., 2011; 
Zecevic, Tremblay, Lovsin and Michel, 2010). Nevertheless, only limited research has examined the relationship between parental support of PA and preschool-age children's PA levels (Dowda et al., 2011; Gubbles et al., 2011; Hinkley, Salmon, Okely, Crawford, 2013; O’Connor et al., 2013; Scharby et al., 2012; Vanderwater et al., 2005; Zecevic et al., 2010). O'Connor et al. (2013) examined parental encouragement and discouragement of PA among Latino children aged 3-5 and determined that parental practices promoting PA, including enrolling children in sports, participating in the child's activities, and modeling of PA, and supporting children's PA behavior. Grigsby-Toussaint, Chi, and Fiese (2011) found that while certain environmental factors, such as a built environment with high levels of green space are important for PA, most increases in preschoolers' PA is due to parental support for PA. A study with preschool-age boys determined that boys who received greater parental support for PA were significantly more likely to engage in 1 hour or more of daily PA than those who did not receive such support (Zecevic et al., 2010). A study by Østbye and colleagues (2013) found that parental attitudes in support of PA were significantly associated with MVPA among preschool-age children. Suen and colleagues (2015) examined parental practices among Hong Kong preschoolers and determined that providing conditional, instrumental, and motivational support to parents motivated them to encourage children to be physically active. On the other hand, parental emphasis on academic achievement, lack of time and resources, promotion of sedentary behaviors, and safety concerns discouraged PA (Suen et al., 2015).

Parental involvement is another influential parental practice as it relates to PA. A study conducted in New Zealand by Oliver et al. (2010) found a positive association between PA of parents and their preschool-aged children, which suggests the potential importance of parental involvement in preschool-based PA intervention such as parents and children 
315 participating together in activities sponsored by the intervention (e.g., Family Fun Nights) and parents direct involvement in intervention activities beyond the intervention environment (e.g.

317 "try this at home").

\section{Parental and/or family influences on television-viewing and other screen-viewing.}

Most studies focusing on parental and family influences on screen-viewing time of young children have focused on TV (Bagley, Salmon \& Crawford, 2006; Barr, Danziger, Hilliard, Andolina, Ruskis, 2010; Certain \& Kahn, 2002; Dalzell, Msall, High, 2000; Dawson-Hahn et al., 2015; Downing, Hinkley, Hesketh, 2015; Dennison BA, Erb TA, Jenkins PL., 2002; Jackson, Djafarian, Stewart, \& Speakman, 2009; Thompson, Polk, Cheah, Vandewater, Johnson, Chrismer,Tschann, 2015; Vandewater, Rideout, Wartella, Huang, Lee, Shim, 2007).

A study by Jackson et al. (2009) of preschool-age children (2-6 years) found that children who watched more TV were significantly less physically active than children who watched less TV. Similarly, a recent cross-sectional study by Dawson-Hahn et al. (2015) conducted among preschool-age children in found that watching TV was inversely associated with PA. Parental attitudes, screen time, and having a television in the bedroom were positive predictors of children's excess screen time and inadequate PA.

Parental education and self-efficacy for PA were negative predictors of screen time (Carson \& Janssen, 2012). A study by Lampard et al (2013) found low-income preschool-age children (2-5 years) were more likely to meet the American Academy of Pediatrics screen time recommendation (no more than 1 hour per day) if their parent reported high restriction of child screen time. Moreover, in multivariate analysis, less parent screen time, fewer parent life pressures, and greater social support were associated with 
338 parents' high restriction of screen time (Lampard et al., 2013). Downing, Hinkley and Hesketh

339 (2015) found that children whose parents limited television viewing spent significantly less

340 time in watching TV and in total screen time; however, overall sedentary behavior was

341 unaffected. Further studies need to be conducted on how family environment influences

342 sedentary behaviors among children.

343 Studies suggest that the TV viewing habits of parents and other family members in the

344 household (e.g., older siblings) likely contribute to the time preschoolers spend watching TV

345 (Downing, Hinkley, Hesketh, 2015; Djafarian, Stewart, \& Speakman, 2009;

346 Thompson,Polk, Cheah, Vandewater, Johnson, Chrismer,Tschann, 2015). The more time that

347 parents spend watching TV the more time their preschool-aged children spend watching TV

348 (Vandewater, Rideout, Wartella, Huang, Lee, Shim, 2007). A similar pattern is found between

349 older siblings' time spent viewing TV and preschool children's time spent viewing

350 (Vandewater, Rideout, Wartella, Huang, Lee, Shim, 2007).

Current research also indicates that many preschoolers' daily screen time exceeds

352 recommendations. Vandewater, Shim, and Caplovitz (2004) determined that preschool

353 children watched more television than primary school children (2.19 hours/day vs. 1.91

354 hours/day), with $61.7 \%$ of children in the preschool group watching television for at least

3552 hours per day.

Other screen-viewing behaviors common among young children include activities

357 such as DVDs/VHS, video games, computers, smartphones, etc (Bagley, Salmon \& Crawford, 358 2006), but to date, these other screen-viewing behaviors have not been extensively examined 359 among preschool-age children. 
Siblings and peer influences. Sibling and peer PA and sedentary behaviors appear to

be important influences on preschool-aged children's PA and sedentary behaviors.

Preschoolers observe and imitate the behaviors of those who are similar to them (Ward et al., 2017). Therefore, siblings and peers may be role models for preschoolers' physical activity. A study conducted in child care centers in Canada found that peers influenced preschoolers' physical activity over time (Ward et al., 2017).

\section{Environmental (Community/Neighborhood) Influences}

Promoting physical activities in neighborhood environments where children spend significant amounts of time can contribute to increased PA levels (Goldfield et al., 2012). Several studies show that being outdoors is the strongest correlate of PA among preschool children and that activity levels correlate with the number of play spaces near their homes and the amount of time spent in those spaces (Hart, Herriot, Bishop, \& Truby, 2003; Lindsay, Sussner, Greaney, \& Peterson, 2009; McKenzie et al., 2008; Roemmich et al., 2006; Salmon et al., 2013). Researching the relationships between built environments and PA is challenging, and designing and implementing supportive environments, corrective programs and policies is complex because environmental factors may vary across children of different demographics (e.g., age, gender, race/ethnicity, SES) and cultural backgrounds (Vandewater et al., 2006).

Weather and season. Natural environments can present barriers to PA. McKee, Murtagh, Boreham, Nevill, and Murphy (2012) examined the influence of season on objectively assessed PA in preschool children in Minnesota and found that children take approximately 2,000 (20\%) fewer steps per day in winter than in Spring. A qualitative study by Lindsay et al. (2009) determined that Latina mothers viewed weather as an important factor influencing their preschool children's PA habits in Massachusetts; during cold weather, 
children spent more time indoors and engaged in less PA, whereas children spent more time outdoors and in parks and recreational facilities during warmer weather. Similarly, additional qualitative studies with parents of young children in Canada and Australia showed that colder weather posed challenges for parents in keeping their preschoolers physically active (He et al., 2005; Pearson, Salmon, Crawford, Campbell, \& Timperio, 2011).

Weather is also an important influence on children's screen time. A qualitative study conducted in six European countries by De Decker and colleagues (2012) found that weather condition was one of the most important factors influencing children's screen time. Researchers suggest that parents should be provided with guidance on alternatives for screen activities and information on how to set rules for screen time to assist them in decreasing their preschool children's screen time.

Time outdoors. The more time preschool children spend outdoors, the higher their PA levels (Boldemann et al., 2006; Burdette, Whitaker, \& Daniels, 2004; Hinkley, Crawford, Salmon, Okely, \& Hesketh, 2008). Several studies included in this review suggest that parents and caregivers can and should encourage outdoor play (Anderson et al., 2008; Ergler, Kearns, \& Witten, 2013; Tandon, Saelens, Zhou, Kerr, \& Christakis, 2013; Veitch, Salmon, \& Ball, 2010). Questions of safety and accessibility, however, can make it more difficult for some parents and children to spend time outdoors. Minority and low-income parents, for example, are more likely to live in communities with fewer parks, sports facilities, bike paths, and other places for children to be active and safe (Lindsay et al., 2009).

\section{Availability and access to PA programs, parks, and recreational facilities.}

Availability and access to PA programs, parks, and recreational facilities are important influences on preschool children's PA. Results from studies reviewed suggest that to support 
406 efforts that promote preschool-age children's PA activity through active play, age-appropriate, 407 outdoor play spaces with access to play equipment should be developed and maintained in communities (Anderson et al., 2008; Burdette \& Whitaker, 2005; Ergler, Kearns, \& Witten, 2013; Tandon, Saelens, Zhou, Kerr, \& Christakis, 2013; Veitch, Salmon, \& Ball, 2010). The concept of neighborhood greenness has also been correlated with preschool-age children and PA. Grigsby-Toussaint et al. (2011) determined that families with preschool-age children who have access to recreational facilities with higher levels of green space are more physically active than are preschoolers without access.

Neighborhood safety. As discussed earlier, a number of studies have demonstrated that perceived lack of neighborhood safety is a potential barrier to preschool children's PA (Burdette \& Whitaker, 2005; Goldfield et al., 2012; Lindsay et al., 2009; Salmon et al., 2003). For example, a cross-sectional survey of 2,445 mothers of 2-3 year old children found that perceived neighborhood safety was a barrier to PA (Burdette, Wadden, \& Whitaker, 2006). Likewise, a qualitative study conducted with Latina mothers in Massachusetts found that mothers reported neighborhood safety as a barrier to PA engagement and to their preschoolage children's active play (Lindsay et al., 2009). On the other hand, research indicates that providing a safe play area and attendants to supervise children increases PA and decreases screen time of young children attending schools near the play areas (Burdette et al., 2006).

\section{Organizational Influences}

Early care and education (ECE) settings. Currently, there are several types of early care and education arrangements in the United States. Broadly, they can be broken down into four types: nurseries/preschools, center-based child care/daycare, family child care homes, and home-based care from nannies/babysitters. Center-based child care is generally provided 
429 in a public building and children are usually grouped by age in classrooms with at least one 430 trained teacher. Most states regulate center-based childcare. Nursery schools and pre-schools 431 are educational establishments or learning spaces offering early childhood education to 432 children between the ages of 3 and 5 years. Like center-based child care, most states regulate 433 nurseries and pre-schools. Family child care is home-based, and providers care for children 434 other than their own in the providers' own home. Family child care may be licensed or 435 unlicensed, and despite the growing interest in this type of setting, further exploration of PA 436 and sedentary in family child care settings is needed because available studies show that PA 437 levels have been low among preschool-age children attending licensed family child care 438 homes (Lindsay et al., 2016; Vanderloo, Martynuik, \& Tucker, 2015). Home-based care 439 provided by a nanny or a babysitter often involve child care hired on a scheduled full- or part440 time basis with care often provided in the child's home.

$441 \quad$ Results of studies included in this review suggest that day care centers and preschools 442 may be able to provide access to outdoor play spaces for young children (Burdette \& 443 Whitaker, 2005; Grigsby-Toussaint et al', 2011), which could foster opportunities to be 444 physically active. A recent study conducted in the U.K. by Hesketh, Griffin \& van Slujis 445 (2015) found that preschool-aged children and particularly boys were less sedentary and more 446 active when in child care compared to at home. Despite opportunities for daycare/child care 447 centers and preschools to provide access to outdoor play spaces for young children some 448 studies have also documented children facing barriers to being physically active in these 449 settings. Using focus groups, Copeland, Kendeigh, Saelens, Kalkwarf, and Sherman (2012) 450 determined that preschool and daycare center teachers believe that PA is important for 451 developing children, but noted that children's inappropriate clothing (e.g., flip-flops or 
sandals, dress/expensive clothes, no hat/gloves or coat during the winter) were barriers to children's PA at the daycare centers (Copeland et al., 2012). Furthermore, results showed that clothing choices were a source of conflict between parents and child-care providers (Copeland et al., 2012). In addition, a recent cross-sectional study conducted in Australia by Hinkley, Salmon, Crawford, Okely \& Hesketh (2016) found that preschool-age children significantly less active during the hours they spent in organized child care than outside care hours.

Quality of early education and care also appears to influence children's PA levels when in these settings. Dowda, Pate, Trost, Almeida, and Sirard (2004) found that children spent more time in sedentary activities at low-quality preschools than did children in highquality preschools.

Other important influences on levels of PA among preschool-age children in ECE settings include adult support and availability of both outdoor space and play equipment. Using direct observation at child care centers, Bower et al. (2008) determined that adult support and availability of play equipment were associated with greater PA and lower sedentary activity levels among preschoolers. Similarly, a study in the Netherlands focusing on preschools and daycare centers found that locations with greater outdoor space and equipment availability reported higher PA levels in the children (Gubbels, Van Kann, \& Jansen, 2012). Likewise a recent study by Schlechter, Rosenkranz, Fees \& Dzewaltowski (2017) found that providing more time outdoors and restructuring preschool activities from whole group to small group could increase the amount of total physical activity that children accumulate during preschool.

\section{Policy Influences}

Need for PA policies in early care and education settings. There has been a growing interest in understanding how policies in ECE settings influence PA behavior and obesity 
476 prevention efforts in young children in the U.S. (Larson, Ward, Neelon, \& Story, 2011).

477 Some studies investigating the role of child care environments in influencing PA levels of

478 preschoolers noted these settings as important venues to promote and support PA among

479 young children, given families' increased reliance on these sites (Gubbels, Van Kann, \&

480 Jansen, et al., 2012; Vanderloo et al., 2014). National trends in the U.S show that about 77\%

481 of children age 3-5 years spend an average of 30 hours weekly in an ECE setting (Buscemi,

482 Kanwischer, Becker, Ward, \& Fitzgibbon, 2015; McPherson \& Homer, 2011). A study by

483 Duffey, Slining, and Benjamin Neelon (2014) investigating ECE policies found that no state

484 in the US had regulations for staff joining children in PA, taking away PA opportunities as a

485 punishment for poor classroom behavior (e.g., taking away recess), or providing

486 training/education on PA for childcare providers. Study results suggested that there is room

487 for improvement in childcare regulations related to PA for young children and that updated

488 regulations are needed (Duffey et al., 2014).

489

National support for PA policies. Some of the leading national health organizations

490 have come to consensus on strategies to support obesity prevention efforts through promotion

491 of PA, reduced screen time, and healthy eating in ECE settings (AAP, American Public Health

492 Association, National Association of Pediatric Nurse Practitioners (NAPNAP), and National

493 Resource Center for Health and Safety in Child Care and Early Education, 2012). With

494 support from the Health Resources and Services Administration, organizations such as the

495 American Academy of Pediatrics, NAPNAP, Maternal Child Health Bureau, American Public

496 Health Association, and the National Resource Center for Health and Safety in Child Care and

497 Early Education have outlined national child care regulations that include PA guidelines for 498 children from birth to 6 years of age (AAP et al., 2012) attending ECE setting. These 
guidelines recommend that preschool-age children engage in 90-120 minutes of ageappropriate MVPA per 8-hour day in an ECE setting. If weather permits, preschool-age children should be given two or three occasions of 60-90 minutes of outdoor play, and that structured activities that promote bodily movement should be led by caregiver/teachers two or more times per day (indoor or outdoor). Another recommendation is to have written policies in ECE settings regarding children's PA while at the ECE. The Institute of Medicine (IOM, 2011) has made policy and policy implementation recommendations for ECE settings, such as the need to increase young children's PA and reduce sedentary behavior, in order to guide care providers and health professionals. The Society of Behavioral Medicine has recommended that state and local policymakers use effective evidence-based models (e.g., Michelle Obama's Let's Move!, Childcare) to implement policies in ECE settings in order to increase PA and reduce sedentary behavior (Buscemi et al., 2015). A recent study in the United States suggested adoption of the Montessori school system as a strategy to promote PA in preschools. Pate et al. (2015) determined that compared to students in traditional preschools, children in Montessori preschools accumulated more light, MVPA, and total PA after adjusting for BMI, sex, SES, and parental education (Pate et al., 2015). Different than traditional school settings where children often sit at their desks for most of the time, children in Montessori programs learn through action and self-discovery, choosing activities and moving about freely during the course of the day (Pate et al., 2015).

In addition, it has been proposed that community policies concerning joint-use agreements related to PA (e.g., school gyms), neighborhood design, and urban planning may increase PA opportunities for preschool-age children (McPherson \& Homer, 2011). 
Research suggests that state regulations, outlined in the National Resource Center for 522 Health and Safety in Child Care and Early Education (2011), lack specificity about PA 523 frequency in ECE settings (Battista et al., 2014; Benjamin, Cradock, Walker, Slining, \& 524 Gillman, 2008; Cradock, O’Donnell, Benjamin, Walker, \& Slining, 2010). This is an area of 525 growing research interest, and additional information is critical to providing directions on 526 ways in which state regulations can help promote early physical activity among young 527 children.

ECE policy change efforts. ECE-level policies and efforts have been supportive 529 influences on preschool-age children's PA behaviors in the U.S. (Gubbels, Slining, et al., 2012; Trost, Ward, \& Senso, 2010), but states inconsistently regulate the implementation of national policies on PA in ECE settings (Buscemi et al., 2015; Gubbels et al., 2012; Larson et al., 2011; McPherson \& Homer, 2011; Vanderloo et al., 2014), and many children do not meet PA levels in childcare centers (Buscemi et al., 2015; Duffey et al., 2014; Vanderloo et al., 534 2014). There have been attempts to develop and implement PA policies in ECEs. For 535 example, in 2007, New York City’s ECE centers implemented new regulations put forth by 536 the New York City Department of Health and Mental Hygiene to reduce screen time, increase 537 PA, and provide healthier beverages (Nonas, Silver, Kettel Khan, \& Leviton, 2004). However, 538 results of recent studies evaluating compliance with these recommendations found that 539 compliance was low for offered PA time (38.5\%) and structured PA time (34.6\%) (Lessard 540 et al., 2014; Nonas et al., 2004).

Barriers to PA policy changes in ECE settings. Some of the barriers to promoting

542 PA in ECE settings that influence adoption of PA regulations are inadequate outdoor/play 543 space, sedentary staff, staff not interested in PA and lack of appropriate equipment (Buscemi 
544 et al., 2015; Nonas et al., 2004). Research gaps in preschool-age children's PA measurements

545 and PA program policy-assessment tools are areas to further explore in ECE sites (Kaciroti,

546 Staples-Watson, \& Lumeng, 2012).

\section{DISCUSSION}

549 to look at the context of and influences on PA for preschool-age children. Our review

550 provides significant evidence for several levels of action to improve the current state of PA for

551 this diverse population. Overall, the two important themes are the importance of increasing

552 access and achieving adult buy-in, including that of parents and child care providers. While

553 policies have focused primarily on the quantity of suggested PA, these twin themes, access to

554 and adult support of PA, could inform future policies and potentially have a positive impact

555 on this important issue.

556 Findings from studies included in this review elucidated multi-level factors at various

557 levels in the social-ecological model that influence preschool-age children's PA levels and

558 behaviors. At the individual level, factors associated with differing levels of PA include SES

559 and the child's sex (Annesi, Smith, \& Tennant, 2013; Bagley et al., 2006; Cespedes et al.,

560 2013; Chuang, Sharman, Skala, \& Evans, 2013; Kumanyika \& Grier, 2006; Montgomery et

561 al., 2004; O’Connor et al., 2014; Pate et al., 2004; Salmon et al., 2003; Sisson et al., 2009;

562 Suen et al., 2015; Vale et al., 2010; Van Cauwenberghe et al., 2012). At the individual level,

563 some factors suggest that the lack of PA may have to do with lack of access or insufficient

564 family resources to make PA a priority (e.g., SES, family structure), while other factors

565 suggest parental values come into play (child's sex and cultural context). 
At the interpersonal level, the presence of siblings, single- versus two-parent family

567 structure, and the parents' culture, parents' PA habits, attitudes toward PA, concerns about the 568 outside environment and their encouragement of PA - are important factors influencing their 569 children's PA (Carson et al., 2014; Davison \& Birch, 2002; De Decker et al., 2012; Oliver et 570 al., 2010; Østbye et al., 2013; Pfeiffer, Dowda, McIver, \& Pate, 2009; Rodriguez-Oliveros et 571 al., 2011). Family time spent watching TV is also an important interpersonal level factor 572 impacting the PA level of young children (Dawson-Hahn et al., 2015; Jackson et al., 2009). In 573 addition, studies suggest that parents can be important mediators of children's sedentary 574 behaviors and should promote other enjoyable alternatives to increase children's level of PA 575 (Salmon et al., 2005). At the interpersonal level, family factors that suggest a need for access 576 include concerns about neighborhood safety and traffic, whereas parents' PA habits and 577 perceptions suggest a need for intervention that address communication, education and 578 provision of guidance for parents regarding the importance of these factors in influencing their 579 children's PA.

At the environmental level, outdoor space_-greenness of the environment, weather 581 and season, access to parks and PA programing, and safety and traffic — was the primary 582 factor (Boldemann et al., 2006; Burdette et al., 2004; Ergler et al., 2013; Grigsby-Toussaint et 583 al., 2011; McKee et al., 2012; McKenzie et al., 2008; Salmon et al., 2013; Tandon et al., 2013; 584 Veitch et al., 2010). At the environmental level, identified factors reflect a need for access to 585 safe and age-appropriate places for young children to be active (safety and traffic, weather and 586 seasons). The fact that "greenness" of the outdoor resources has an impact on PA suggests 587 that making the outdoor space desirable as well as useable is important. At the institutional 
588 level, not all EEC facilities have equal resources, and, access is an issue (e.g., availability of 589 indoor and outdoor space for PA, access to age-appropriate equipment, etc.).

At the organizational level, in the context of the ECE settings, teacher/caregiver

591

592

593

594

595

596

597

598

599

600

601

602

603

604

605

606

607

608

609

610

support of PA, play equipment, and outdoor space were important factors associated with PA of children while at the EEC setting (Bower et al., 2008; Copeland et al., 2012; Dowda et al., 2004; Gubbels, Kremer, et al., 2012; Reilly, 2010).

At the policy level, there is much room for improvement. While the National Association for Sport and Physical Education, AAP, and IOM have clear PA guidelines for preschool-age children (AAP et al., 2012; IOM, 2011; NASPE, 2009), compliance is low (Lessard et al., 2014; Nonas et al., 2004).

\section{CONCLUSIONS}

PA is a key component of overall physical, social, and mental health (AAP, 2006; Goldfield et al., 2012; Hodges et al., 2013; O’Dwyer et al., 2012). Helping children set the foundation for healthful PA habits early in life is a key component for achieving longer and healthier lives for individuals and the general population. Promoting PA in early childhood requires attention to the child and also caregivers - the home, early care and education (e.g., child care centers, family child care homes, etc.), and community settings in which care and development of children take place. Despite an increasing number of studies focusing on the PA of young children, much remains to be learned about the many factors — such as parenting practices and styles, sociocultural factors, and environmental factors (including childcare settings) - that influence the development and maintenance of PA and sedentary behaviors among preschool-age children and, consequently, the development of obesity in childhood (Lindsay, Sussner, Kim, \& Gortmaker, 2006; Lindsay et al., 2009). 
Since children's PA habits are initiated very early in life, early PA promotion

612

613

614

615

616

617

630

631

632

633

634

635

636

637

638

639

640

641

642

643

644 illnesses, they are well positioned to work with parents to promote and support the

645

programs and intervention may not only have immediate health benefits, but may also help

reduce chronic disease risks when learned, healthful PA habits and preferences are carried into adulthood (Davison, Edmunds, et al., 2011; Lindsay et al., 2006; Tremblay et al., 2011). This

literature provides a comprehensive synthesis of factors related to PA of young children at multiple levels of influence that could be targeted in interventions.

\section{How Might this Information Affect Nursing Practice?}

This review provides a comprehensive synthesis of factors related to PA levels and behaviors of young children that could assist pediatric nurses in their daily health promotion and disease prevention efforts with families of young children and in the development of childhood obesity prevention interventions.

With reducing and preventing childhood obesity remaining a public health priority, nurses will continue to be engaged in childhood obesity prevention efforts through practice, research, and education. PA assessment should be integrated as part of well-child visit assessments in pediatric nursing primary care tasks of screening, communication and anticipatory counseling. Integrating such assessment into electronic medical records would help pediatric nurses routinely monitor children's PA behaviors as part of children's overall health status assessment, creating opportunities to communicate to parents the importance of early PA habits as part of their child's overall health. Given pediatric nurses' roles as primary care providers and their frequent and continued contact with parents and children throughout the early childhood years through well-child visits, immunization schedule, and minor acute development of healthful early physical activity behaviors of young children. Pediatric nurses 
646 can play an important role in facilitating communication, education and provision of guidance

647 for parents regarding the importance of PA as well as factors influencing their children's PA

648 levels and behaviors. Nurses may be able to facilitate children's access to PA opportunities is

649 by providing parents with information and anticipatory guidance about various types of

650 physical activities which are developmentally appropriate for young children, as well as list of

651 local places free-of-cost or low-cost where young children and their families can be active.

652

653 REFERENCES

654 American Academy of Pediatrics (AAP). (2006). Active healthy living: Prevention of

655 childhood obesity through increased physical activity. Pediatrics, 117, 1834-1842.

656 American Academy of Pediatrics (AAP), American Public Health Association, and National

657 Resource Center for Health and Safety in Child Care and Early Education. (2012).

$658 \quad$ Preventing childhood obesity in early care and education programs: Selected

659 standards from caring for our children (2nd ed.). Retrieved from

660 http://nrckids.org/default

661 /assets/File/PreventingChildhoodObesity2nd.pdf

662 Anand S, Krosnick JA. Demographic predictors of media use among infants, toddlers, and

663 preschoolers. Am Behav Sci. 2005;48(5):539-561. doi: 10.1177/0002764204271512.

664 Annesi, J. J., Smith A. E., \& Tennant, G. A. (2013). Effects of the Start for Life treatment

665 on physical activity in primarily African American preschool children of ages 3-5

666 years. Psychology, Health, and Medicine, 18(3), 300-309.

667 doi: $10.1080 / 13548506.2012 .712704$ 
668 669

670

671

672

673

674

675

676

677

678

679

680

681

682

683

684

685

686

687

688

689

Ariza, A. J., Chen E. H., Binns H. J., Christoffel K. K. (2004) Risk factors for overweight in five- to six-year-old Hispanic-American children: a pilot study. J Urban Health.;81(1):150-61.

Asplund KM, Kair LR, Arain YH, Cervantes M, Oreskovic NM, Zuckerman KE. (2015).

Early Childhood Screen Time and Parental Attitudes

Toward Child Television Viewing in a Low-Income Latino Population Attending the Special Supplemental Nutrition Program for Women, Infants, and Children.

Child Obes.,11(5):590-9. doi: 10.1089/chi.2015.0001. Epub 2015 Sep 21.

Bagley, S., Salmon, J., \& Crawford, D. (2006). Family structure and children's television viewing and physical activity. Medicine \& Science in Sports \& Exercise, 38(5), 910918.

Ball SC, Gillman MW, Mayhew M, Namenek Brouwer RJ, Benjamin Neelon SE. (2015) Physical activity-related and weather-related practices of child care centers from 2 states. $J$ Phys Act Health., 12(2):238-44. doi: 10.1123/jpah.2013-0266. Epub 2014 Apr 17.

Barr R, Danziger C, Hilliard M, Andolina C, Ruskis J. (2010). Amount, content and context of infant media exposure: a parental questionnaire and diary analysis. Int J Early Years Educ. 18(2):107-122. doi: 10.1080/09669760.2010.494431.

Battista, R. A., Oakley, H., Weddell, M. S., Mudd, L. M., Greene, J. B., \& West, S. T. (2014). Improving the physical activity and nutrition environment through self-assessment (NAP SACC) in rural area child care centers in North Carolina. Preventive Medicine, 67(Suppl 1), S10-16. doi:10.1016/j.ypmed.2014.01.022. 
690

691

692

693

694

695

696

697

698

699

700

701

702

703

704

705

706

707

708

709

710

711

712

Baumrind D. (1971). Current patterns of parental authority. Developmental Psychology Monograph, Part 2, 4 (1): 1-103.

Beets, M. W., Bornstein, D., Dowda, M., \& Pate, R. R. (2011). Compliance with national guidelines for physical activity in U.S. preschoolers: Measurement and interpretation. Pediatrics, 127(4), 658-664. doi:10.1542/peds.2010-2021

Bélanger M, Humbert L, Vatanparast H, Ward S, Muhajarine N, Chow AF, Engler-Stringer R, Donovan D, Carrier N, Leis A. (2016). A multilevel intervention to increase physical activity and improve healthy eating and physical literacy among young children (ages 3-5) attending early childcare centres: the Healthy Start-Départ Santé cluster randomised controlled trial study protocol. BMC Public Health. 12;16:313. doi: 10.1186/s12889-016-2973-5.

Benjamin, S. E., Cradock, A., Walker, E. M., Slining, M., \& Gillman, M. W. (2008). Obesity prevention in child care: A review of U.S. state regulations. BMC Public Health, 30(8), 188. doi:10.1186/1471-2458-8-188.

Bentley GF, Turner KM, Jago R. (2016) Mothers' views of their preschool child's screenviewing behaviour: a qualitative study. BMC Public Health, 16:718. doi: 10.1186/s12889-016-3440-z.

Boldemann, C., Blennow, M., Dal, H., Mårtensson, F., Raustorp, A., Yuen, K., \& Wester, U. (2006). Impact of preschool environment upon children's physical activity and sun exposure. Preventive Medicine, 42, 301-308.

Bower, J. K., Hales, D. P., Tate, D. F., Rubin, D. A., Benjamin, S. E., \& Ward, D. S. (2008). The child care environment and children's physical activity. American Journal of Preventive Medicine, 34(1), 23-29. 
Burdette, H. L., Wadden, T. A., \& Whitaker, R. C. (2006). Neighborhood safety, collective efficacy, and obesity in women with young children. Obesity, 14(3), 518-525.

Burdette, H. L., \& Whitaker, R. C. (2005). Resurrecting free play in young children: Looking beyond fitness and fatness to attention, affiliation, and affect. Archives of Pediatric and Adolescent Medicine, 159(1), 46-50.

Burdette, H. L., Whitaker, R. C., \& Daniels, S. R. (2004). Parental report of outdoor playtime as a measure of physical activity in preschool-aged children. Archives of Pediatric and Adolescent Medicine, 158(4), 353-357.

Buscemi, J., Kanwischer, K., Becker, A. B., Ward, D. S., \& Fitzgibbon, M. L. (2015). Society of Behavioral Medicine position statement: Early care and education (ECE) policies can impact obesity prevention among preschool-aged children. Translational Behavioral Medicine, 5(1), 122-125.

Carlson SA, Fulton JE, Lee SM, Foley JT, Heitzler C, Huhman M. (2010). Influence of limitsetting and participation in physical activity on youth screen time. Pediatrics., 126(1):e89-96. doi: 10.1542/peds.2009-3374.

Carson, V., \& Janssen, I. (2012). Associations between factors with the home setting and screen time among children aged 0-5 years: A cross-sectional study. BMC Public Health, 12, 539. doi:10.1186/1471-2458-12-539.

Carson, V., Stearns, J., \& Janssen, I. (2015). The Relationship Between Parental Physical Activity and Screen Time Behaviors and the Behaviors of their Young Children. Pediatr Exerc Sci., 27(3):390-5. doi: 10.1123/pes.2014-0214.

Cerin E, Baranowski T, Barnett A, Butte N, Hughes S, Lee RE, Mendoza JA, Thompson D, O'Connor TM. (2016). Places where prechoolers are (in) active: an observational 
study on Latino preschoolers and their parents using objective measures. Int J Behav Nutr Phys Act. 29;13:29. doi: 10.1186/s12966-016-0355-0.

Certain LK, Kahn RS. (2002). Prevalence, correlates, and trajectory of television viewing among infants and toddlers. Pediatrics. 109(4):634-642. doi: 10.1542/peds.109.4.634

Cespedes, E. M., McDonald, J., Haines, J., Bottino, C. J., \& Taveras, E. M. (2013). Obesityrelated behaviors of U.S. and non-U.S. born parents and children in low-income households. Journal of Developmental and Behavioral Pediatrics, 34(8), 541-548.

Chen, T. A., O’Connor, T. M., Hughes, S. O., Frankel, L., Baranowski, J., Mendoza, J. A., Thompson, D., \& Baranowski, T. (2013). TV parenting practices: Is the same scale appropriate for parents of children of different ages? International Journal for Behavioral Nutrition and Physical Activity, 10(41). doi:10.1186/1479-5868-10-41.

Cheng S, Maeda T, Yoichi S, Yamagata Z, Tomiwa K. (2010). Early television exposure and children's behavioral and social outcomes at age 30 months. J Epidemiol. 20(Suppl 2):S482-S489.

Chuang R. J., Sharman S., Skala, K., \& Evans, A. (2013). Ethnic differences in the home environment and physical activity behaviors among low-income, minority preschoolers in Texas. American Journal of Health Promotion, 27(4), 270-278. doi:10.4278/ajhp $.110427-Q U A N-171$

Commonwealth of Australia, Department of Health and Ageing. (2010). Move and play every day: National physical activity recommendations for children 0 to 5 years. Retrieved from http://www.health.gov.au/internet/main/publishing.nsf/content 


\section{/9D831D9E6713F92ACA257BF0001F5218/\$File/0-5yrACTIVE_Brochure}

\section{FA\%20SCREEN.pdf}

Copeland, K. A., Kendeigh, C. A., Saelens, B. E., Kalkwarf, H. J., \& Sherman, S. N. (2012). Physical activity in child-care centers: Do teachers hold the key to the playground? Health Education Research, 27(1), 81-100.

Copeland KA, Sherman SN, Khoury JC, Foster KE, Saelens BE, Kalkwarf HJ. (2011). Wide variability in physical activity environments and weather-related outdoor play policies in childcare centers within a single county of Ohio. Arch Pediatr Adolesc Med.,165(5):435-42. doi: 10.1001/archpediatrics.2010.267. Epub 2011 Jan 3.

Copeland KA, Khoury JC, Kalkwarf HJ. (2016). Child Care Center Characteristics Associated With Preschoolers' Physical Activity. Am J Prev Med., 50(4):470-9. doi: 10.1016/j.amepre.2015.08.028.

Cradock, A. L., O’Donnell, E. M., Benjamin, S. E., Walker, E., \& Slining, M. (2010). A review of state regulations to promote physical activity and safety on playgrounds in child care centers and family child care homes. Journal of Physical Activity and Health, 7(Suppl 1), S108-119.

Davison, K. K., \& Birch, L. L. (2002). Obesogenic families: Parents’ physical activity and dietary intake patterns predict girls' risk of overweight. International Journal of Obesity, 26, 1186-1193.

Davison, K. K., Edmunds, L. S., Wyker, B. A., Young, L. M., Sarfoh, V. S., \& Sekhobo, J. P. (2011). Feasibility of increasing childhood outdoor play and decreasing television viewing through a family-based intervention in WIC, New York State, 2007-2008. Prevention of Chronic Disease, 8, A54. 
Dawson-Hahn, E. E., Fesinmeyer, M. D., \& Mendoza, J. A. (2015). Correlates of physical activity in Latino preschool children attending Head Start. Pediatric Exercise Science, 27(3), 372-379. doi:10.1123/pes.2014-0144.

Dalzell VP, Msall ME, High PC. (2000). Parental attitudes of television and videocassette viewing of children aged birth to 36 months. J Dev Behav Pediatr. 21(5):390.

De Decker, E., De Craemer, M., De Bourdeaudhuij, I., Wijndaele, K., Duvinage, K., Koletzko, B., ... Cardon, G. (2012). Influencing factors of screen time in preschool children: An exploration of parents' perceptions through focus groups in six European countries. Obesity Review, (Suppl 1), 75-84. doi:10.1111/j.1467-789X.2011.00961.x.

Dennison BA, Erb TA, Jenkins PL. (2002). Television viewing and television in bedroom associated with overweight risk among low-income preschool children. Pediatrics. 109(6):1028-35.

Department of Health, Physical Activity, Health Improvement and Protection. (2011). Start active, stay active: A report on physical activity for health from the four home countries' Chief Medical Officers. London, England: Author.

Dowda, M., Pate, R., Trost, S., Almeida, M., \& Sirard, J. (2004). Influences of preschool policies and practices on children's physical activity. Journal of Community Health, 29, 183-196.

Dowda, M., Pfeiffer K. A., Brown W. H., Mitchell J. A., Byun W., Pate R. R. (2011) Parental and environmental correlates of physical activity of children attending preschool. Arch Pediatr Adolesc Med. 165(10):939-44. doi: 10.1001/archpediatrics.2011.84. Epub 2011 Jun 6. 
Downing KL, Hinkley T, Hesketh KD. (2015). Associations of Parental Rules and Socioeconomic Position With Preschool Children's Sedentary Behaviour and Screen Time. J Phys Act Health., 12(4):515-21. doi: 10.1123/jpah.2013-0427.

Duffey, K. J., Slining, M. M., \& Benjamin Neelon, S. E. (2014). States lack physical activity policies in child care that are consistent with national recommendations. Childhood Obesity, 10(6), 491-500. doi:10.1089/chi.2014.0096

Dwyer, G. M., Higgs, J., Hardy, L. L., \& Baur, L. A. (2008). What do parents and preschool staff tell us about young children's physical activity: A qualitative study. International Journal of Behavioral Nutrition and Physical Activity, 5, 66. doi:10.1186/1479-58685-66

Dwyer, J., Needham, L., Simpson, J. R., \& Heeney, E. S. (2008). Parents report intrapersonal, interpersonal, and environmental barriers to supporting healthy eating and physical activity among their preschoolers. Applied Physiology, Nutrition, and Metabolism, 33(2), 338-46. doi:10.1139/H07-195.

Edwards MJ, Jago R, Sebire SJ, Kesten JM, Pool L, Thompson JL. The influence of friends and siblings on the physical activity and screen viewing behaviours of children aged 56 years: a qualitative analysis of parent interviews. BMJ Open., 5(5):e006593. doi: 10.1136/bmjopen-2014-006593.

Ekelund, U., Brage, S., \& Wareham, N. J. (2004). Physical activity in young children. Lancet, 363(9415), 1163-1164.

Ergler, C. R., Kearns, R. A., \& Witten, K. (2013). Seasonal and locational variations in children's play: Implications for wellbeing. Social Science Medicine, 91, 178-185. 
827 Fakhouri, T. H., Hughes, J. P., Brody, D. J., Kit, B. K., \& Ogden, C. L. (2013). Physical

828

829

830

831

832

833

834

835

836

837

838

839

840

841

842

843

844

845

846

847

848

849

activity and screen-time viewing among elementary school-aged children in the United States from 2009 to 2010. JAMA Pediatrics, 167(3), 223-229.

Finch M, Wolfenden L, Falkiner M, Edenden D, Pond N, Hardy LL, Milat AJ, Wiggers J. (2012). Impact of a population based intervention to increase the adoption of multiple physical activity practices in centre based childcare services: a quasi experimental, effectiveness study. Int $J$ Behav Nutr Phys Act. 29;9:101. doi: 10.1186/1479-5868-9-101.

Finn, K., Johannsen, N., \& Specker, B. (2002). Factors associated with physical activity in preschool children. Journal of Pediatrics, 140(1), 81-85.

Fitzgibbon, M.L., Stolley, M.R., Schiffer, L.A., Braunschweig, C.L., Gomez, S.L., Van Horn L., Dyer, A.R. (2011). Hip-Hop to Health Jr. Obesity Prevention Effectiveness Trial: post-intervention results. Obesity (Silver Spring).;19(5):994-1003. doi:

10.1038/oby.2010.314.

Fitzgibbon, M.L., Stolley, M.R., Schiffer, L.A., Van Horn L., Christoffel K.K., Dyer, A.R. (2006). Hip-Hop to Health Jr. for Latino Preschool Children. Obesity 14 (9): 16171625.

Gallagher MR. (2010). Maternal perspectives on lifestyle habits that put children of Mexican descent at risk for obesity. J Spec Pediatr Nurs.;15(1):16-25. doi: 10.1111/j.17446155.2009.00213.x.

Garriguet D, Carson V, Colley RC, Janssen I, Timmons BW, Tremblay MS. (2016). Physical activity and sedentary behavior of Canadian children aged 3 to 5 . Health Rep. 21; 27(9):14-23. 
Goldfield, G. S., Harvey, A., Grattan, K., \& Adamo, K. B. (2012). Physical activity promotion in the preschool years: A critical period to intervene. International Journal of Environmental Research and Public Health, 9(4), 1326-1342.

Grigsby-Toussaint, D. S., Chi, S. H., \& Fiese, B. H. (2011). Where they live, how they play: Neighborhood greenness and outdoor physical activity among preschoolers. International Journal of Health Geography, 10, 66.

Gubbels, J. S., Kremer, S. P., Van Kann, D. H., Stafleu, A., Candel, M. J., Dagnelie, P. C., ... de Vries, N. K. (2012). Interaction between physical environment, social environment, and child characteristics in determining physical activity at child care. Health Psychology, 30(1), 84-90.

Gubbels, J. S., Van Kann, D. H., \& Jansen, M. W. (2012). Play equipment, physical activity opportunities, and children's activity levels at child care. Journal of Environmental and Public Health, 2012. doi:10.1155/2012/326520

Gubbels J. S., Kremers S. P. J., Stafleu A., de Vries SI, Goldbohm RA, Dagnelie PC, de Vries NK, van Buuren S, Thijs C. (2011). Association between parenting practices and children's dietary intake, activity behavior and development of body mass index: the KOALA birth cohort study. International Journal of Behavioral Nutrition and Physical Activity. 8, article 18 doi: 10.1186/1479-5868-8-18.

Hnatiuk JA, Ridgers ND, Salmon J, Hesketh KD. (2016). Maternal correlates of young children's physical activity across periods of the day. J Sci Med Sport. 14. pii: S14402440(16)30119-0. doi: 10.1016/j.jsams.2016.06.014. 
871 Hart, K. H., Herriot, A., Bishop, J. A., \& Truby, H. (2003). Promoting healthy diet and

872

873

874

875

876

877

878

879

880

881

882

883

884

885

886

887

888

889

890

891 exercise patterns amongst primary school children: A qualitative investigation of parental perspectives. Journal of Human Nutrition and Dietetics, 16, 89-96.

He, M., Irwin, J. D., Sangster Bouck, L. M., Tucker, P., \& Pollett, G. L. (2005). Screenviewing behaviors among preschoolers: Parents' perceptions. American Journal of Preventive Medicine, 29, 120-125. doi:10.1016/j.amprepe.2005.04.004

Hesketh KR, Griffin SJ, van Sluijs EM. (2015). UK Preschool-aged children's physical activity levels in childcare and at home: a cross-sectional exploration. Int J Behav Nutr Phys Act., 26, 12:123. doi: 10.1186/s12966-015-0286-1.

Hesketh, K. R., Goodfellow, L., Ekelund, U., McMinn, A. M., Godfrey, K. M., Inskip, H. M., ... van Sluijs, E. M. F. (2014). Activity levels in mothers and their preschool children. Pediatrics, 133(4), 973-980.

Hesketh, K. R., McMinn, A. M., Griffin, S. J., Harvey, N. C., Godfrey, K. M., Inskip, H. M., ... van Sluijs, E. M. (2013). Maternal awareness of young children's physical activity: Levels and cross-sectional correlates of overestimation. BMC Public Health, 13, 924.

Hinkley, T., Crawford, D., Salmon, J., Okely, A. D., \& Hesketh, K. (2008). Preschool children and physical activity: A review of correlates. American Journal of Preventive Medicine, 34(5), 435-441.

Hinkley, T., Salmon, J., Okely, A. D., Crawford, D., \& Hesketh, K. (2011). Influences on preschool children's physical activity: Exploration through focus groups. Family and Community Health, 34(1), 39-50. 
Hinkley T., Salmon J., Okely A. D., Crawford D. (2013). The correlates of preschoolers' compliance with screen recommendations exist across multiple domains. Preventive Medicine. 57(3):212-219. doi: 10.1016/j.ypmed.2013.05.020.

Hinkley T, Salmon J, Crawford D, Okely AD, Hesketh KD. (2016). Preschool and childcare center characteristics associated with children's physical activity during care hours: an observational study. Int J Behav Nutr Phys Act. 11;13(1):117.

Hodges, E. A., Smith, C., Tidwell, S., \& Berry, D. (2013). Promoting physical activity in preschoolers to prevent obesity: A review of the literature. Journal of Pediatric Nursing, 28(1), 3-19.

Horodynski MA, Stommel M, Brophy-Herb HE, Weatherspoon L. (2010). Mealtime television viewing and dietary quality in low-income African American and Caucasian mother-toddler dyads. Matern Child Health J. 14(4):548-556. doi: 10.1007/s10995009-0501-2.

Institute of Medicine (IOM). (2011). Early childhood obesity prevention policies. Washington, DC: The National Academies Press.

Jackson, D. M., Djafarian, K., Stewart, J., \& Speakman, J. R. (2009). Increased television viewing is associated with elevated body fatness but not with lower total energy expenditure in children. American Journal of Clinical Nutrition, 89(4), 1031-1036. doi:10.3945/ajen.2008.26746

Jones, S., Hendricks, S., \& Draper, C. E. (2014). Assessment of physical activity and sedentary behavior at preschools in Cape Town, South Africa. Childhood Obesity, 10(6), 501-510. doi:10.1089/chi.2014.0097 
Kaciroti, N., Staples-Watson, J., \& Lumeng, J. C. (2012). Enhancing self-regulation as a strategy for obesity prevention in Head Start preschoolers: The growing healthy study. BMC Public Health, 30(12), 1040.

Kelly, L. A., Reilly, J. J., Fisher, A., Montgomery, C., Williamson, A., McColl, J. H., ... Grant, S. (2006). Effect of socioeconomic status on objectively measured physical activity. Archives of Disease in Childhood, 91(1), 35-38. doi:10.1136/adc.2005.080275.

Kourlaba G, Kondaki K, Liarigkovinos T, Manios Y. (2009). Factors associated with television viewing time in toddlers and preschoolers in Greece: the GENESIS study. $J$ Public Health (Oxf) 31(2):222-230. doi: 10.1093/pubmed/fdp011.

Kuepper-Nybelen, J., Lamerz, A., Bruning, N., Hebebrand, J., Herpertz-Dahlmann, B., \& Brenner, H. (2005). Major differences in prevalence of overweight according to nationality in preschool children living in Germany: Determinants and public health implications. Archives of Disease in Childhood, 90, 359-363.

Kumanyika, S., \& Grier, S. (2006). Targeting interventions for ethnic minority and lowincome populations. Future Child, 16(1), 187-207.

Lampard AM, Jurkowski JM, Davison KK. (2013). The family context of low-income parents who restrict child screen time. Child Obes., 9(5):386-92. doi: 10.1089/chi.2013.0043.

Lapierre MA, Piotrowski JT, Linebarger DL. (2012). Background television in the homes of US children. Pediatrics. 2012;130(5):839-846. doi: 10.1542/peds.2011-2581.

LaRowe TL, Tomayko EJ, Meinen AM, Hoiting J, Saxler C, Cullen B; Wisconsin Early Childhood Obesity Prevention Initiative (WECOPI). (2016) Active Early: oneyear policy intervention to increase physical activity among early care and education 
programs in Wisconsin. BMC Public Health., 16:607. doi: 10.1186/s12889-016-31983.

Larson, N., Ward, D. S., Neelon, S. B., \& Story, M. (2011). What role can child-care settings play in obesity prevention? A review of the evidence and call for research efforts. Journal of the American Dietetic Association, 111(9), 1343-1362.

Lessard, L., Lesesne, C., Kakietek, J., Breck, A., Jernigan, J., Dunn, L., ... Khan, L. K. (2014). Measurement of compliance with New York City's regulations on beverages, physical activity, and screen time in early child care centers. Prevention of Chronic Disease, 16(11), E183. doi:10.5888/pcd11.130433.

Levin S, Martin MW, Riner WF. (2004). TV viewing habits and body mass index among South Carolina Head Start children. Ethn Dis. ;14(3):336-9.

Lindsay AC, Greaney ML, Wallington SF, Sands FD, Wright JA, Salkeld J. (2017). Latino parents' perceptions of the eating and physical activity experiences of their preschool children at home and at family child-care homes: a qualitative study. Public Health Nutr.;20(2):346-356. doi: 10.1017/S136898001600207X.

Lindsay, A. C., Sussner, K. M., Greaney, M. L., \& Peterson, K. E. (2009). Influence of social context on eating, physical activity, and sedentary behaviors of Latina mothers and their preschool-age children. Health Education and Behavior, 36, 81-96.

Lindsay, A. C., Sussner, K. M., Kim, J., \& Gortmaker, S. L. (2006). The role of parents in preventing childhood obesity. Future Child, 16(1), 169-186.

Linebarger DL, Walker D. (2005) Infants' and toddlers' television viewing and language outcomes. Am Behav Sci. 48(5):624-645. doi: 10.1177/0002764204271505. 
959 960

961 962

963

964

965

966

967

968

969

970

971

972

973

974

975

976

977

978

979

980

981

Loprinzi, P. D., \& Trost, S. G. (2010). Parental influences on physical activity behavior in preschool children. Preventive Medicine, 50(3), 129-133.

Lumeng JC, Rahnama S, Appugliese D, Kaciroti N, Bradley RH. (2006). Television exposure and overweight risk in preschoolers. Arch Pediatr Adolesc Med. 160(4):417-422. doi: 10.1001/archpedi.160.4.417.

Manios Y, Kondaki K, Kourlaba G, Grammatikaki E, Birbilis M, Ioannou E. (2009). Television viewing and food habits in toddlers and preschoolers in Greece: the GENESIS study. Eur J Pediatr.168(7):801-808. doi: 10.1007/s00431-008-0838-3.

Masur EF, Flynn V. (2008). Infant and mother-infant play and the presence of the television. $J$ Appl Dev Psychol. 29(1):76-83. doi: 10.1016/j.appdev.2007.10.001.

McLeroy, K. R., Bibeau, D., Steckler, A., \& Glanz, K. (1988). An ecological perspective on health promotion programs. Health Education Quarterly, 15(4), 351-377.

McKee, D. P., Murtagh, E. M., Boreham, C. A., Nevill, A. M., \& Murphy, M. H. (2012). Seasonal and annual variation in young children's physical activity. Medicine \& Science in Sports \& Exercise, 44(7), 1318-1324. doi:10.1249/MSS.0b013e3182464db5

McKenzie, T. L., Baquero, B., Crespo, N. C., Arredondo, E. M., Campbell, N. R., \& Elder, J. P. (2008). Environmental correlates of physical activity in Mexican American children at home. Journal of Physical Activity and Health, 5(4), 579-591.

McLeroy, K. R., Bibeau, D., Steckler, A., \& Glanz, K. (1998). An ecological perspective on health promotion programs. Health Education Quarterly, 15(4), 351-377.

McLearn KT, Minkovitz CS, Strobino DM, Marks E, Hou W. (2006). The timing of maternal depressive symptoms and mothers' parenting practices with young children: 
implications for pediatric practice. Pediatrics. 118(1):e174-e182. doi: 10.1542/peds.2005-1551.

McPherson, M. E., \& Homer, C. J. (2011). Policies to support obesity prevention for children: A focus on of early childhood policies. Pediatric Clinics of North America, 58(6), $1521-1541$

Mendelsohn AL, Dreyer BP, Brockmeyer CA, Berkule-Silberman SB, Huberman HS, Tomopoulos S. (2011). Randomized controlled trial of primary care pediatric parenting programs: effect on reduced media exposure on infants, mediated through enhanced parent-child interaction. Arch Pediatr Adolesc Med. 165(1):42-48. doi: 10.1001/archpediatrics.2010.266.

Mendoza, J. A., Zimmerman, F. J., \& Christakis, D. A. (2007). Television viewing, computer use, obesity, and adiposity in US preschool children. International Journal of Behavioral Nutrition and Physical Activity, 4, 44.

Montgomery, C., Reilly, J., Jackson, D., Kelly, L. A., Slater, C., Paton, J. Y., \& Grant, S. (2004). Relation between physical activity and energy expenditure in a representative sample of young children. American Journal of Clinical Nutrition, 80(3), 591-596.

National Association for Sport and Physical Education (NASPE). (2009). Active start: A statement of physical activity guidelines for children from birth to age 5 (2nd ed.). Sewickley, PA: American Alliance for Health, Physical Education, Recreation, and Dance.

National Resource Center for Health and Safety in Child Care and Early Education (NRC), University of Colorado Denver. (2011). Achieving a state of healthy weight: A 
national assessment of obesity prevention terminology in Child Care Regulations 2010. Aurora, CO: Author.

Nonas, C., Silver, L. D., Kettel Khan, L., \& Leviton, L. (2004). Rationale for New York City's regulations on nutrition, physical activity, and screen time in early child care centers. Prevention of Chronic Disease, 11, E182. doi:10.5888/pcd11.130435

O’Connor, T. M., Cerin, E., Hughes, S. O., Robles, J., Thompson, D., Baranwoski, T., ... Shewchuk, R. M. (2013). What Hispanic parents do to encourage and discourage 3-4 year old children to be active: A qualitative study using nominal group technique. International Journal of Behavioral Nutrition and Physical Activity, 10, 93. doi:10.1186/1479-5868-10-93

O’Connor, T. M., Cerin, E., Lee, R. E., Parker, N., Chen, T. A., Hughes, S. O., ... Baranowski, T. (2014). Environmental and cultural correlates of physical activity parenting practices among Latino parents with preschool-aged children: Niños activos. BMC Public Health, 14, 707. doi:10.1186/1471-2458-14-707

O’Connor, T. M., Chen, T. A., Baranowski, J., Thompson, D., \& Baranowski, T. (2013). Physical activity and screen-media-related parenting practices have different associations with children's objectively measured physical activity. Childhood Obesity, $9(5), 446-453$.

O’Dwyer, M. V., Fairclough, S. J., Knowles, Z., \& Stratton, G. (2012). Effect of a family focused active play intervention on sedentary time and physical activity in preschool children. International Journal of Behavioral Nutrition and Physical Activity, 9(1), 113. 
1026

1027

1028

1029

1030

1031

1032

1033

1034

1035

1036

1037

1038

1039

1040

1041

1042

1043

1044

1045

1046

1047

Okely, A. D., Salmon, J., Trost, S. G., \& Hinkley, T. (2008). Discussion paper for the development of physical activity recommendations for children under five years. Canberra, Australia: Commonwealth Department of Health and Ageing.

Oliver, M., Schofield, G. M., \& Schluter, P. J. (2010). Parent influences on preschoolers' objectively assessed physical activity. Journal of Science and Medicine in Sport, 13(4), 403-409.

Østbye, T., Malhotra, R., Stroo, M., Lovelady, C., Brouwer, R., Zucker, N., Fuemmeler, B. (2013). The effect of the home environment on physical activity and dietary intake in preschool children. International Journal of Obesity (London), 37(10), 1314-21. doi:10.1038/ijo.2013.76

Pate, R. R., O’Neill, J. R., Brown, W. H., Pfeiffer, K. A., Dowda, M., \& Addy, C. L. (2015). Prevalence of Compliance with a New Physical Activity Guideline for Preschool-Age Children. Childhood Obesity, 11(4), 415-420. doi:10.1089/chi.2014.0143

Pate, R. R., Pfeiffer, K. A., Trost, S. G., Ziegler, P., \& Dowda, M. (2004). Physical activity among children attending preschools. Pediatrics, 114, 1258-1263.

Pearson, N., Salmon, J., Crawford, D., Campbell, K., \& Timperio, A. (2011). Are parental concerns for child TV viewing associated with child TV viewing and the home sedentary environment? International Journal of Behavioral Nutrition and Physical Activity, 8, 102. doi:10.1186/1479-5868-8-102

Pfeiffer, K. A., Dowda, M., McIver, K. L., \& Pate, R. R. (2009). Factors related to objectively measured physical activity in preschool children. Pediatric Exercise Science, 21(2), 196-208. 
1048 Pratt, M., Epping, J. N., \& Dietz, W. H. (2009). Putting physical activity into public health: A 1049 historical perspective from the CDC. Preventive Medicine, 49(4), 301-302.

1050 Prochaska, JO.; DiClemente, CC. The transtheoretical approach. In: Norcross, JC; Goldfried, 1051 MR. (eds.) Handbook of psychotherapy integration. 2nd ed. New York: Oxford

1052 University Press; 2005. p.147-171.

1053

Rodríguez-Oliveros, G., Haines, J., Ortega-Altamirano, D., Power, E., Taveras, E. M., 1054 González-Unzaga, M. A., \& Reyes-Morales, H. (2011). Obesity determinants in 1055 1056 Mexican preschool children: Parental perceptions and practices related to feeding and physical activity. Archives of Medical Research, 42(6), 532-539.

1057

1058

1059

1060

1061

1062

1063

1064

1065

1066

1067

1068

1069

Roemmich, J. N., Epstein, L. H., Raja, S., Yin, L., Robinson, J., \& Winiewicz, D. (2006). Association of access to parks and recreational facilities with the physical activity of young children. Preventive Medicine, 43(6), 437-441.

Rosenstock, I. (1974). Historical Origins of the Health Belief Model. Health Education Monographs. Vol. 2 No. 4.

Ruiz, R., Gesell, S. B., Buchowski, M. S., Lambert, W., \& Barkin, S. L. (2011). The relationship between Hispanic parents and their preschool-aged children's physical activity. Pediatrics, 127(5), 888-895.

Sallis JF, Cervero RB, Ascher W, Henderson KA, Kraft MK, Kerr J. (2006). An ecological approach to creating active living communities. Annu Rev Public Health., 27:297-322.

Salmon, J., Ball, K., Crawford, D., Booth, M., Telford, A., Hume, C., ... Worsley, A. (2005). Reducing sedentary behaviour and increasing physical activity among 10-year-old 

children: Overview and process evaluation of the "switch-play" intervention. Health Promotion International, 20(1), 7-17.

Salmon, J., Owen, N., Crawford, D., Bauman, A., \& Sallis, J. F. (2003). Physical activity and sedentary behavior: A population-based study of barriers, enjoyment, and preference. Health Psychology, 22(2), 178-188.

Salmon, J., Veitch, J., Abbott, G., ChinAPaw, M., Brug, J. J., teVelde, S. J., ... Ball, K. (2013). Are associations between the perceived home and neighbourhood environment and children's physical activity and sedentary behaviour moderated by urban/rural location? Health Place, 24, 44-53. doi:10.1016/j.healthplace.2013.07.010

Sawyer, A., Smith, L., Schrempft, S., van Jaarsveld, C. H., Wardle, J., \& Fisher, A. (2014). Primary caregiver knowledge of paediatric physical activity recommendations in the United Kingdom and its association with caregiver behaviour: An observational study. BMC Public Health, 14, 795. doi:10.1186/1471-2458-14-795.

Schary D. P., Cardinal B. J., Loprinzi P. D. (2012). Parental support exceeds parenting style for promoting active play in preschool children. Early Child Development and Care. 182(8):1057-1069. doi: 10.1080/03004430.2012.685622.

Schlechter CR, Rosenkranz RR, Fees BS, Dzewaltowski DA. Preschool Daily Patterns of Physical Activity Driven by Location and Social Context. J Sch Health. 2017 Mar;87(3):194-199. doi: 10.1111/josh.12486.

Sigmundová D, Sigmund E, Badura P, Vokáčová J, Trhlíková L, Bucksch J. (2016). Weekday-weekend patterns of physical activity and screen time in parents and their preschoolers. BMC Public Health,16:898. doi: 10.1186/s12889-016-3586-8. 
1092 Sisson, S. B., Church, T. S., Martin, C. K., Tudor-Locke, C., Smith, S. R., Bouchard, C., ...

1093

1094

1095

1096

1097

1098

1099

1100

1101

1102

1103

1104

1105

1106

1107

1108

1109

1110

1111

1112

1113 Katzmarzyk, P. T. (2009). Profiles of sedentary behavior in children and adolescents: The U.S. National Health and Nutrition Examination Survey, 2001-2006. International Journal of Pediatric Obesity, 4(4), 353-359.

Schmidt ME, Rich M, Rifas-Shiman SL, Oken E, Taveras EM. (2009). Television viewing in infancy and child cognition at 3 years of age in a US cohort. Pediatrics. 123(3):e370e375. doi: 10.1542/peds.2008-3221.

Smith BJ, Grunseit A, Hardy LL, King L, Wolfenden L, Milat A. (2010). Parental influences on child physical activity and screen viewing time: a population based study. $B M C$ Public Health.,10:593. doi: 10.1186/1471-2458-10-593.

Stephens RL, Xu Y, Lesesne CA, Dunn L, Kakietek J, Jernigan J, Khan LK. (2014). Relationship between child care centers' compliance with physical activity regulations and children's physical activity, New York City, 2010. Prev Chronic Dis., 11:E179. doi: $10.5888 / \operatorname{pcd} 11.130432$.

Soltero EG, Cerin E, Lee RE, O'Connor TM. (2016). Associations Between Objective and Self-Report Measures of Traffic and Crime Safety in Latino Parents of Preschool Children. J Immigr Minor Health. 1-12. doi:10.1007/s10903-016-0498-8. Sep 28. [Epub ahead of print]

Tandon PS, Walters KM, Igoe BM, Payne EC, Johnson $\quad$ DB. (2016). Physical Activity Practices, Policies and Environments in Washington State Child Care Settings: Results of a Statewide Survey. Matern Child Health J., 2016 Jul 22. [Epub ahead of print] 
1114 Tandon, P. S., Saelens, B. E., Zhou, C., Kerr, J., \& Christakis, D. A. (2013). Indoor versus outdoor time in preschoolers at child care. American Journal of Preventive Medicine, 44(1), 85-88.

1117 Taylor, R. W., Murdoch, L., Carter, P., Gerrard, D. F., Williams, S. M., \& Taylor, B. J. (2009). Longitudinal study of physical activity and inactivity in preschoolers: The FLAME study. Medicine \& Science in Sports \& Exercise, 41(1), 96-102.

The World Bank. Data High income: OECD. 2013.

1121 Thompson AL, Adair LS, Bentley ME. (2013). Maternal characteristics and perception of temperament associated with infant TV exposure. Pediatrics. 131(2):e390-e397. doi: 10.1542/peds.2012-1224.

Thompson DA, Christakis DA. (2007). The association of maternal mental distress with television viewing in children under 3 years old. Ambulatory Pediatr. 7(1):32-37. doi:

1127 Thompson D.A., Polk S, Cheah C.S., Vandewater E.A., Johnson S.L., Chrismer M.C., 1128 Tschann J.M. (2015). Maternal Beliefs and Parenting Practices Regarding Their Preschool Child's Television Viewing: An Exploration in a Sample of Low-

1132 Thompson DA, Christakis DA. (2005). The association between television viewing and 1133 irregular sleep schedules among children less than 3 years of 1134 age. Pediatrics. 116(4):851-856. doi: 10.1542/peds.2004-2788. 
1135 Thompson DA, Sibinga EM, Jennings JM, Bair-Merritt MH, Christakis DA. (2010).

1136

1137

1138

1139

1140

1141

1142

1143

1144

1145

1146

1147

1148

1149

1150

1151

1152

1153

1154

1155

1156

1157

Television viewing by young Hispanic children: evidence of heterogeneity. Arch Pediatr Adolesc Med. 164(2):174-179. doi: 10.1001/archpediatrics.2009.257.

Tomopoulos S, Dreyer BP, Valdez P. et al. (2007). Media content and externalizing behaviors in Latino toddlers. Ambulatory Pediatr. 7(3):232-238. doi: 10.1016/j.ambp.2007.02.004.

Tonge KL, Jones RA, Hagenbuchner M, Nguyen TV, Okely AD. (2017). Educator engagement and interaction and children's physical activity in early childhood education and care settings: an observational study protocol. BMJ Open. 7;7(2):e014423. doi: 10.1136/bmjopen-2016-014423.

Toselli S, Zaccagni L, Celenza F, Albertini A, Gualdi-Russo E. (2015). Risk factors of overweight and obesity among preschool children with different ethnic background. Endocrine. 2015 Aug;49(3):717-25. doi: 10.1007/s12020-014-0479-4.

Tremblay, M. S., Leblanc, A. G., Carson, V., Choquette, L., Connor Gorber, S., Dillman, C., ... Timmons, B. W. (2012). Canadian physical activity guidelines for the early years (aged 0 to 4 years). Applied Physiology, Nutrition, and Metabolism, 37(2), 370-391.

Tremblay, M. S., LeBlanc, A. G., Kho, M. E., Saunders, T. J., Larouche, R., Colley, R. C., ... Gorber, S. C. (2011). Systematic review of sedentary behaviour and health indicators in school-aged children and youth. International Journal of Behavioral Nutrition and Physical Activity, 8, 98. doi:10.1186/1479-5868-8-98

Trost, S. G., Ward, D. S., \& Senso, M. (2010). Effects of child care policy and environment on physical activity. Medicine \& Science in Sports \& Exercise, 42(2), 520-525. doi:10.1249/MSS.0b013e3181cea3ef . 
1158 Tucker P, Vanderloo LM, Burke SM, Irwin JD, Johnson AM. (2015). Prevalence and 1159 influences of preschoolers' sedentary behaviors in early learning centers: a crosssectional study. BMC Pediatr., 15:128. doi: 10.1186/s12887-015-0441-5.

1161 Vale, S., Santos, R., Soares-Miranda, L., Silva, P., \& Mota, J. (2010). Compliance with physical activity guidelines in preschool children. Journal of Sports Science, $28(6), 603-608$.

1164 Van Cauwenberghe, E., Jones, R. A., Hinkley, T., Crawford, D., \& Okely, A. D. (2012). Patterns of physical activity and sedentary behavior in preschool children. International Journal of Behavioral Nutrition and Physical Activity, 27(9), 138.

Vanderloo LM, Tucker P. (2015). Weekly trends in preschoolers' physical activity and 1168 sedentary time in childcare. ,Int $J$ Environ Res Public Health.,12(3):2454-64. doi: 10.3390/ijerph120302454.

Vanderloo LM, Tucker P, Johnson AM, Burke SM, Irwin JD. (2015) Environmental Influences on Preschoolers' Physical Activity Levels in Various Early-Learning Vanderloo, L. M., Martynuik, O. J. M., \& Tucker, P. (2015). Physical and sedentary activity 1175 Facilities. Res Q Exerc Sport., 86(4):360-70. doi: 10.1080/02701367.2015.1053105. J. D. (2014). The influence of center-based child care on preschoolers' physical levels among preschoolers in home-based child care: A systematic review. Journal of Physical Activity and Health, 12(6), 879-889. doi:10.1123/jpah.2013-0483 activity levels: A cross-sectional study. International Journal of Environmental Research and Public Health, 11(2), 1794-1802. 
1181

1182

1183

1184

1185

1186

1187

1188

1189

1190

1191

1192

1193

1194

1195

1196

1197

1198

1199

1200

1201

1202

1203

Vandewater, E. A., Bickham, D. S., \& Lee, J. H. (2006). Time well spent? Relating television use to children's free-time activities. Pediatrics, $117(2), 181-191$.

Vandewater, E. A., Shim, M. S., \& Caplovitz, A. G. (2004). Linking obesity and activity level with children's television and video game use. Journal of Adolescents, 27(1), 71-85.

Vandewater E. A., Park S.-E., Huang X., Wartella E. A. (2005). "No-you can't watch that": parental rules and young children's media use. American Behavioral

Scientist. 48(5):608-623. doi: 10.1177/0002764204271497.

Vandewater EA, Rideout VJ, Wartella EA, Huang X, Lee JH, Shim MS. (2007). Digital childhood: electronic media and technology use among infants, toddlers, and preschoolers. Pediatrics. 119(5):e1006-e1015. doi: 10.1542/peds.2006-1804.

Vandewater EA, Bickham DS, Lee JH, Cummings HM, Wartella EA, Rideout VJ. (2005). When the television is always on - Heavy television exposure and young children's development. Am Behav Sci. 48(5):562-577. doi: 10.1177/0002764204271496.

Veitch, J., Hume, C., Salmon, J., Crawford, D., \& Ball, K. (2013). What helps children be more active and less sedentary? Perceptions of mothers living in disadvantaged neighbourhoods. Child Care Health Development, 39(1), 94-102.

Veitch, J., Salmon, J., \& Ball, K. (2010). Individual, social and physical environmental correlates of children active free-play: A cross-sectional study. International Journal of Behavioral Nutrition and Physical Activity, 2, 7-11.

Ward S, Bélanger M, Donovan $\quad \mathrm{D}$, Boudreau J, Vatanparast $\quad H$, Muhajarine $\quad \mathrm{N}$, Leis A, Humbert ML, Carrier N. (2017). "Monkey see, monkey do": Peers' behaviors predict preschoolers' physical activity and dietary intake in childcare centers. Prev Med. 10;97:33-39. doi: 10.1016/j.ypmed.2017.01.001. 
1204 Zecevic, C. A., Tremblay, L., Lovsin, T., \& Michel, L. (2010). Parental influence on young 1205 children's physical activity. International Journal of Pediatrics, 2010, 468-526. 1206 doi:10.1155/2010/468526.

1207 Zimmerman FJ, Christakis DA. (2005). Children's television viewing and cognitive 1208 outcomes: a longitudinal analysis of national data. Arch Pediatr Adolesc 1209 Med. 159(7):619-625. doi: 10.1001/archpedi.159.7.619.

1210 Zimmerman FJ, Christakis DA, Meltzoff AN. (2007). Television and DVD/video viewing in 1211 children younger than 2 years. Arch Pediatr Adolesc Med. 161(5):473-479. doi: $1212 \quad$ 10.1001/archpedi.161.5.473.

1213

1214

1215

1216

1217

1218 